\title{
A usabilidade do produto de moda - análise das tarefas do usuário na criação e produção do vestuário
}

The usability of the fashion product - analysis of user tasks in the creation and production of clothing

Tamissa Juliana Barreto Berton

Mestranda em Design PPGDesign-UNESP tamiju@gmail.com

\section{Gisely A. Pires Mestre PPGDesign-UNESP pires.gisely@gmail.com}

Marizilda dos S. Menezes PPGDesign-UNESP zilmenez@uol.com.br

\section{Luis C. Paschoarelli}




\title{
A usabilidade do produto de moda - análise das tarefas do usuário na criação e produção do vestuário
}

\author{
The usability of the fashion product - analysis of user tasks in the creation and \\ production of clothing
}

Tamissa Juliana Barreto Berton, Gisely A. Pires, Marizilda dos S. Menezes e Luis C. Paschoarelli

\section{Resumo}

O vestuário é um objeto que está em contato direto com o corpo e, quando mal projetado, pode limitar o indivíduo nas suas atividades cotidianas, considerando assim, a usabilidade do produto. $\mathrm{O}$ artigo visa realçar a análise das tarefas do usuário durante o desenvolvimento do projeto de produto de moda, demonstrando em quais etapas o conhecimento dos movimentos realizados pelo homem devem estar inseridos. Ao evidenciar as fases do projeto, desde a pesquisa e criação até a modelagem, momento em que é iniciada a construção do produto, é notável a influência da ergonomia e antropometria nesse processo, sendo que o conhecimento do corpo humano em sua totalidade é essencial para a construção da roupa. Para isso, foi realizada uma revisão bibliográfica para unir os conceitos necessários a fim de concretizar o objetivo do trabalho. Os assuntos abordados têm como finalidade conscientizar o designer de moda do quanto a compreensão das atividades do usuário influenciará na qualidade do produto projetado.

Palavras- chave: design de moda, análise de tarefas, vestuário.

\begin{abstract}
Clothing is an object that is in direct contact with the body, and when poorly designed can limit the individual in the daily activities, thus considering the usability of the product. This article aims to highlight the analysis of user tasks during the development of the fashion product design, showing in which steps the knowledge of movements performed by man shall be inserted. By showing stages, from research and creation until modeling, at which begins the construction of the product, it is remarkable the influence of ergonomics and anthropometry in the process, and the knowledge of the human body in its entirety is essential for the construction of clothing. For this, a literature review was performed to unite the concepts necessary to achieve the objective of the work. The subjects covered are intended to educate the fashion designer as understanding the user's activities will influence the quality of the designed product.
\end{abstract}

Keywords: fashion design, task analysis, clothing. 


\section{Introdução}

O vestuário é um artefato que está em contato primário com o corpo humano e quando é desenvolvido sem que sejam consideradas as demandas de uso, pode resultar em desconforto, ineficiência e limitações ao usuário. Para evitar esta situação, é necessário destacar um quesito que nem sempre é explorado durante o desenvolvimento do produto de moda: a análise das tarefas realizadas pelo usuário e, consequentemente, os movimentos do corpo humano.

Alguns autores abordados no decorrer deste artigo como Jones (2005), Sanches (2008) e Martins (2008) apontam que além dos diversos fatores de ordem estética que estão diretamente atrelados ao produto de moda, também devem ser analisados requisitos práticos que possibilitem a efetiva usabilidade do vestuário.

Portanto, existe a necessidade do designer de moda observar e analisar os movimentos praticados pelo usuário durante a atividade exercida enquanto $o$ produto/vestuário é utilizado. Isto ocorre naquelas situações em que o produto de moda é voltado para a prática de atividades físicas, como por exemplo, com intuito de uma melhora de desempenho pelo atleta. Fora esta realidade esportiva, o projeto de desenvolvimento do produto de moda conta pouco com esse tipo de análise.

Neste artigo serão abordados os conceitos de ergonomia e antropometria destinados para áreas afins, que auxiliam na demonstração das características do corpo humano, de suas medidas e mobilidades, com intuito de relacionar estes aspectos com a concepção e o desenvolvimento do produto, considerando principalmente a etapa da modelagem.

\section{Materiais e Métodos}

Com a finalidade de relevar a análise da tarefa do usuário durante o planejamento do vestuário, busca-se um levantamento sobre os processos do projeto de produto voltados para o design de moda, para que se identifique esse fator durante tal procedimento e demonstre como a pesquisa e o conhecimento do público pelo profissional, sendo ele estilista ou modelista, pode auxiliar no processo de criação do produto, inovando ou aperfeiçoando o objeto. 
A análise das tarefas direciona o trabalho aos conceitos de ergonomia e antropometria, e por fim, à modelagem, que consiste no primeiro momento da construção do produto de moda, sendo esta, uma etapa em que podem ser aplicadas tais conceitos.

Portanto, os procedimentos metodológicos utilizados neste estudo caracterizam-se como revisão bibliográfica, uma vez que, através da análise dos diferentes conceitos, foi possível aprofundar e relacionar as abordagens aqui evidenciadas.

Dentre os principais materiais utilizados estão livros, artigos, entre outros meios para a busca desses conhecimentos, de modo que se unam dados e informações sobre o assunto abordado, ressaltando o tema proposto.

O tipo de pesquisa utilizado é a exploratória, tendo em vista que o ponto abordado necessita de fundamentos de áreas afins.

\section{Desenvolvimento do Produto de Moda}

De acordo com Souza e Menezes (2013), no desenvolvimento do produto de moda, a matéria-prima têxtil é projetada para delinear um espaço em torno do corpo, caracterizando silhuetas que definem linhas e volumes, e mantém o corpo como suporte em uma relação de proximidade ou distanciamento. Assim, a roupa está em contato primário com o corpo humano, uma vez que o produto de moda ou vestimenta é considerada uma segunda pele (MARTINS, 2008), sendo um produto de interface direta com a superfície do corpo, proporcionando ao consumidor "trocar de pele".

No produto do vestuário, assim como em qualquer objeto, há uma grande exigência com a inovação. E para que sejam desenvolvidos produtos corretos é imprescindível que exista uma estratégia de novos produtos, especificando quais são os produtos desejados pela empresa. Para Baxter (2000) é a equipe de desenvolvimento do produto a encarregada pela implantação de tal estratégia na empresa.

O produto de moda é sazonal, está em constante transformação, primeiramente porque precisamos de roupas apropriadas para as diferentes estações do ano, e também para determinadas ocasiões dependendo até de formalidades sociais, entre outros fatores mais específicos. Levando em consideração que (de modo geral) os vestuários são frágeis, e sua troca é essencial por uma questão prática e de uso, o objeto 
de moda tem sua obsolescência programada, portanto o seu desenvolvimento carece ser ágil (JONES, 2005).

Dessa forma, a roupa necessita de rapidez neste processo, pois como sua troca é constante, o designer deve estar sempre em sintonia com o seu público e com as estratégias mercadológicas das empresas, para que se consiga atender esse usuário, inovando, não somente na parte estética, mas também evoluindo na questão da usabilidade do produto.

Sanches (2008) apresenta o desenvolvimento de produto de moda em quatro fases, sendo estas: planejamento, geração de alternativas, avaliação e detalhamento, e por fim, a produção. Em três destas etapas, os movimentos do corpo humano deveriam ser levados em consideração. Na fase de planejamento, estão sendo coletados os dados, analisadas as informações e definindo metas, mantendo o foco nas necessidades de quem usufrui do objeto. Na geração de alternativas, as ideias e as possibilidades de produtos começam a se concretizar, através de ferramentas que auxiliam o designer como o desenho, a modelagem tridimensional, a informática, entre outros. Na fase de avaliação e detalhamento são especificados todos os materiais, aviamentos, recortes, costuras, entre os demais detalhes das alternativas selecionadas, definindo todos os itens necessários através de fichas técnicas, modelagens e protótipos.

Para que o produto de moda tenha o desempenho esperado, antes de iniciar a sua produção é fundamental a passagem por esses processos, evitando o risco de erros e ampliando as efetivas possibilidades de satisfação do usuário. Segundo Baxter (2000), deve-se investir mais tempo e competência no decorrer dos estágios iniciais, pois custam menos, sendo isto um dos principais fatores de sucesso do produto.

Cada um desses procedimentos leva em consideração o público-alvo, pois todos os produtos são planejados e executados para serem utilizados, de algum modo, pelo usuário (BAXTER, 2000).

Este usuário deve ser o foco do projeto, uma vez que a análise de suas atividades durante o uso do produto, deve ser já considerada quase toda no primeiro momento do desenvolvimento, o planejamento, onde estão sendo levantados os dados do público-alvo e tomando os devidos direcionamentos para serem iniciadas as ideias.

Para que a cultura da cópia seja substituída pela cultura da inovação, os criadores devem possuir uma visão mais abrangente, não ficando restritos apenas à 
reprodução de tendências de moda. É preciso ir além, deve-se aprofundar no universo do público em questão e compreendê-lo, determinando suas tendências específicas, ou seja, decifrando comportamentos influenciados pela cultura social através de códigos estéticos, buscando conquistar essas pessoas (SANCHES, 2008).

Conhecer o usuário é fundamental para a concretização de produtos inovadores e eficazes, não sendo abordado apenas o seu gosto pessoal - seu estilo - mas também o seu cotidiano, suas efetivas atividades.

Existem muitos fatores que influenciam os consumidores na compra de um produto de moda, muitas vezes os fatores visuais, como as tendências, são atrativos para o consumidor, mas a utilidade e funcionalidade do produto também podem e devem ser considerados como diferencial, pois ajudam a garantir a confiabilidade do objeto.

De acordo com Martins (2008), a usabilidade representa a interface que permite tornar os produtos mais eficazes, transformando-os em artefatos agradáveis e prazerosos durante o uso. A mesma autora continua afirmando que esta usabilidade é um fator essencial para analisar o relacionamento entre produto e usuário.

O ser humano deve ser estabelecido como ponto de partida para a elaboração de qualquer produto, o fator responsável pela sua relação de usabilidade com a roupa é a ergonomia e seus estudos, garantindo o seu conforto e bem-estar. No processo de elaboração do produto é a modelagem que utiliza diretamente os conceitos ergonômicos para garantir a eficiência de uso.

\section{Modelagem}

Para Spaine e Menezes (2013), a modelagem se baseia em um processo responsável pela elaboração dos moldes, que transferem as dimensões e formas do corpo humano para o estilo apresentado pelo designer de moda .

O início dessa técnica dá-se com base no conhecimento do aspecto físico (dados anatômicos) e das dimensões antropométricas do usuário, com referência na parte do corpo a ser vestida e o tipo de roupa que será confeccionada (GOMES FILHO, 2006).

Os moldes do produto do vestuário são confeccionados para a montagem dos protótipos e assim, adequar a vestimenta ao corpo humano, para isto, é necessário 
obter as dimensões do usuário em questão e analisar todas as dimensões da parte do corpo que se pretende vestir.

Boueri (2008) afirma que aqueles que almejam se sobressair no projeto do vestuário precisam ter a noção de escala, de proporções e dimensões. Segundo o autor, esses quesitos são necessários para o projeto de produto do vestuário, pois para que a peça se acomode e se movimente harmoniosamente, o designer de moda necessita conhecer o básico de antropometria: as dimensões, os movimentos cinesiológicos, a anatomia e sua forma, e a complexa estrutura do corpo do usuário.

A elaboração de um molde depende de fatores ergonômicos, da antropometria e do conhecimento do corpo do usuário. Dessa forma, para desenvolver a modelagem plana industrial, os elementos principais a serem ponderados são as formas, as dimensões e os movimentos do corpo humano (SPAINE; MENEZES, 2013).

Consequentemente, inicia-se o processo de avaliação e detalhamento do produto, em que as dimensões adequadas devem ser aplicadas aos moldes, considerando também as medições adquiridas através da antropometria. A modelagem do vestuário em sua maioria está baseada apenas nas tabelas de dimensões convencionais, que normalmente não é relevado o movimento que o corpo humano realizará ao utilizar a vestimenta.

A construção da roupa e a escolha do material resultarão na liberdade de movimentos de pessoas vestidas, assim este processo é fundamental para a mobilidade, podendo comprometer movimentos extremos. Entretanto, ao se desenvolver uma modelagem devem ser realizados estudos mais específicos sobre os movimentos do usuário ao desempenhar suas tarefas (MENEGUCCI; SANTOS FILHO, 2013).

Assim, compreende-se que a modelagem, além de ser uma fase importante para a concretização do produto de moda, também pode ser muito específica e delicada, envolvendo dimensões precisas do público a quem está sendo destinada a roupa.

\section{Ergonomia e Antropometria}

Baxter (2000) afirma que a análise das atividades dos usuários incluem dois aspectos significativos do desenvolvimento de produtos: a ergonomia e a antropometria. Para o autor, a ergonomia começou analisando o homem e seu ambiente de trabalho, 
mas com o passar dos anos e a ampliação tecnológicas ela estendeu seus objetivos, visto que estuda também as relações e interações de pessoas com objetos em geral e o seu meio-ambiente, usando os conhecimentos de anatomia, fisiologia e psicologia, para aplicá-los ao projeto de objetos.

As características que definem um grupo de consumidores de acordo com o perfil antropométrico são a idade, o gênero, a forma do corpo, a raça, a capacidade física e a atividade exercida (BOUERI, 2008). Todos estes aspectos são consideráveis para o desenvolvimento do produto de moda, pois a modelagem utiliza do conhecimento do corpo humano e das suas dimensões para o projeto e construção da roupa.

Para concretizar esses dados, Spaine e Menezes (2013) colocam que a antropometria é a ciência que busca dados das múltiplas dimensões corporais encontradas em sua totalidade, como tamanhos, volumes, formas, proporções, movimentos e articulações .

Como a peça do vestuário fica em contato imediato com o corpo, torna-se primordial centrar-se no usuário e nas suas capacidades, necessidades e limitações, relacionando com sua faixa etária, mobilidade e atividade realizada.

Para que as dimensões antropométricas sejam precisas, deve-se detalhar o cálculo matemático durante o traçado das bases, pois pode ser bastante relevante no caimento da roupa se forem utilizadas as proporções entre as partes do corpo e a disposição exata das linhas de equilíbrio, além de torná-la ergonomicamente adequada (SPAINE \& MENEZES, 2013).

Considerando a importância do detalhamento das dimensões corporais, examina-se a maneira mais adequada para adquirir a medição do corpo humano, de modo que seja ponderada a mobilidade de seus membros.

Boueri (2008) subdivide a antropometria em duas áreas: antropometria Estática ou Estrutural e antropometria Dinâmica ou Funcional. A primeira consiste no levantamento das dimensões do corpo em posições estáticas, já utilizadas em um padrão, o da tabela de dimensões. Para lida (2005) o uso desta característica antropométrica é aconselhada somente para projetos de produtos direcionados à usuários que realizam poucos movimentos durante uma atividade muito específica. 
As Figuras 1 e 2 representam as variáveis obtidas por meio da antropometria estática, sendo algumas delas relevantes ao produto do vestuário, principalmente a largura e a altura de partes específicas onde o corpo é vestido, assim como cintura, ombros, quadril, tronco, braços, pernas, entre outros. 
Figura 1: Medida do corpo estático para Boueri

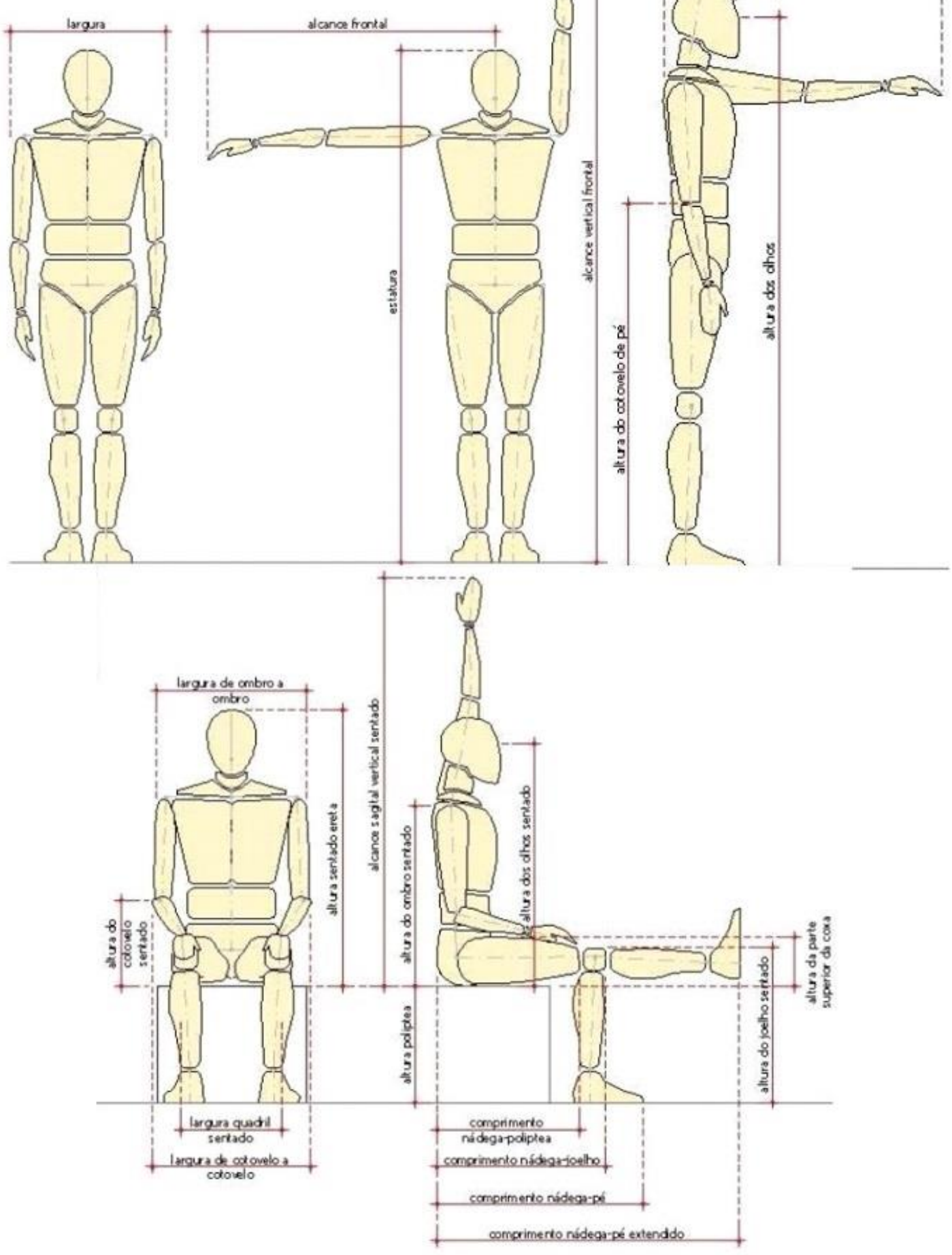

Fonte: Boueri, 2004, p.108. 
Figura 2: Medida do corpo estático para lida

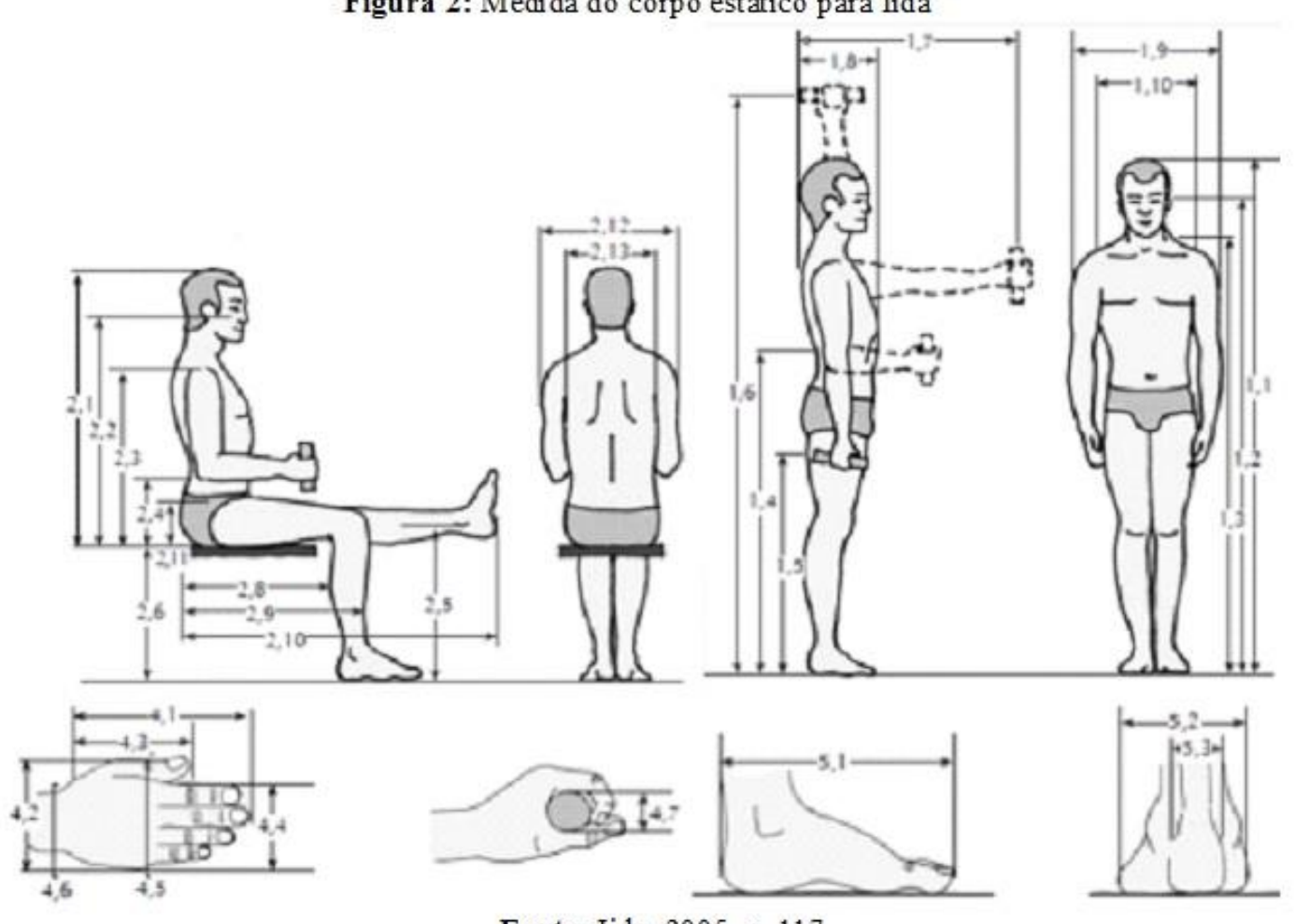

Fonte: Iida, 2005, p. 117.

Fazendo uma comparação entre as Variáveis do corpo estático em pé de Boueri (2008) e Iida (2005), observa-se que o primeiro (Figura 1) ressalta as variáveis de largura, estatura, alcance vertical frontal (com o braço esticado para cima, mede-se da base do pé até a mão), alcance frontal (considera-se no meio da cabeça até as pontas dos dedos), altura do cotovelo de pé (mede-se da base do pé ao cotovelo), altura dos olhos (base do pé até a linhas dos olhos), largura do corpo de perfil e alcance horizontal sagital (de perfil, com o braço esticado para frente é considerado do início das costas até as pontas dos dedos). Já o segundo (Figura 2) analisa as seguintes variáveis: estatura do corpo ereto, estatura dos olhos em pé e ereto, altura dos ombros, altura do cotovelo, altura do centro da mão em pé com o braço pendido, altura do centro da mão em pé com o braço erguido, comprimento do braço na horizontal até o centro da mão, profundidade do corpo na altura do tórax, largura dos ombros em pé e largura dos quadris em pé.

Cada autor nomeia de sua maneira cada medição, mesmo assim nota-se que a maioria das mensurações são semelhantes, mesmo que lida detalhe algumas medições a mais que Boueri, sendo elas: altura do centro da mão em pé com o braço pendido, largura dos quadris em pé e, altura dos ombros. Percebe-se também uma variáveç diferente abordada por Boueri, a dimensão de alcance frontal. Assim, é nítida a 
semelhança entre as duas teorias e unindo-as podem se completar, e ao adaptá-las ao produto de moda possibilitam aprimorar o trabalho do estilista e do modelista.

Quanto ao corpo sentado (Figura 1), Boueri abrange na mensuração da antropometria estática as dimensões: largura de ombro a ombro, altura sentado ereta, altura do cotovelo sentado, largura do quadril sentado, largura de cotovelo à cotovelo, alcance sagital vertical sentado (sentado e com o braço esticado para cima mede-se da base do quadril até as pontas dos dedos), altura do ombro sentado, altura dos olhos sentado, altura poliptea (parte inferior da coxa), altura do joelho sentado, altura da parte superior da coxa, comprimento nádega-poliptea, comprimento nádega-joelho, comprimento nádega-pé, e por fim comprimento nádega-pé extendido (BOUERI, 2008).

Já de acordo com Iida, as dimensões no corpo sentado são (Figura 2): altura da cabeça a partir do assento com o tronco ereto, altura dos olhos a partir do assento com o tronco ereto, altura dos ombros a partir do assento com o tronco ereto, altura do cotovelo a partir do assento com o tronco ereto, altura do joelho sentado, altura poplítea, comprimento do antebraço na horizontal até o centro da mão, comprimento nádegapoliptea, comprimento nádega-joelho, comprimento nádega-pé com a perna extendida na horizontal, altura da parte superior das coxas, largura entre os cotovelos, largura do quadril sentado (IIDA, 2005).

Analisando os dois autores, quanto as dimensões do corpo na postura sentada, Iida aborda a mais apenas a dimensão do comprimento do antebraço, na horizontal até o centro da mão, as outras mensurações são semelhantes. Portanto para realizar uma modelagem direcionada ao vestuário mais básico, onde o foco não é nenhuma atividade que exija grande movimentação do usuário, a antropometria estática auxilia bem o profissional.

A antropometria Dinâmica ou Funcional aborda as dimensões do corpo no decorrer de um movimento aliado à uma atividade, geralmente utilizada em projetos de modelagem esportivo (BOUERI, 2008). Para Iida (2005) a ergonomia Dinâmica calcula os alcances dos movimentos, sendo que o movimento de cada parte do corpo é mensurado com o resto do corpo estático. Neste sentido, a ergonomia Funcional estaria relacionada à tarefas específicas, observando que cada parte do corpo não se move isoladamente. 
Os movimentos e rotações realizados pelo corpo humano, de acordo com Boueri, estão representados pelas Figuras 3 e 4, sendo elas analisadas no plano sagistal e frontal, respectivamente.

Na Figura 3, entre as dimensões e as angulações de deslocamento de cada movimento estão: a ação da articulação do ombro até o cotovelo e da articulação do ombro até o pulso. Quanto a ação da perna, aponta da articulação do quadril até o joelho e do quadril até o tornozelo.

$\mathrm{Na}$ Figura 4, observam-se as seguintes possibilidades: do braço proporcionado pela articulação do ombro até o cotovelo e do ombro até o pulso; do pulso quanto a mão; o levantamento do ombro com referência o peito, o pescoço, cintura para o tronco, enfim, considera todas as articulações, suas possibilidades e limitações de movimento.

\section{Figura 3: Medida do Corpo Dinâmica / Lateral}

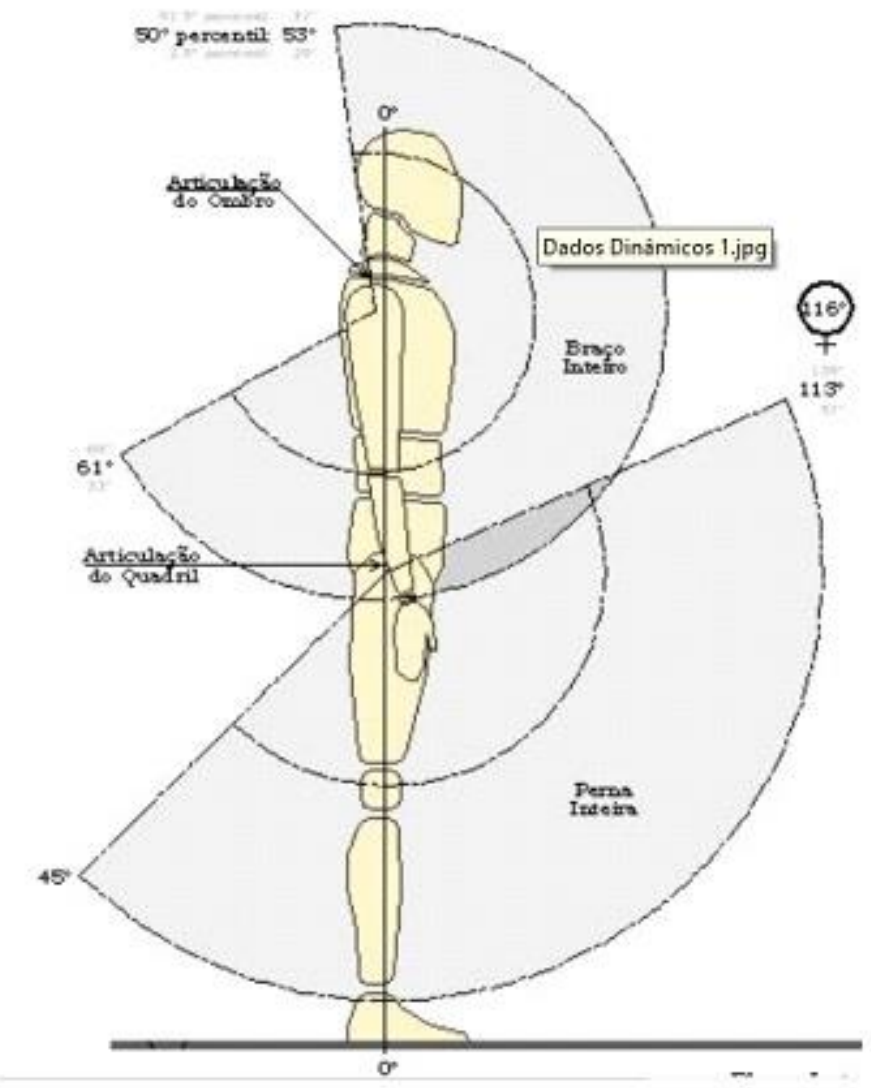

Fonte: Boueri, 2010, p.64. 
Figura 4: Medida do Corpo Dinâmica / Frontal

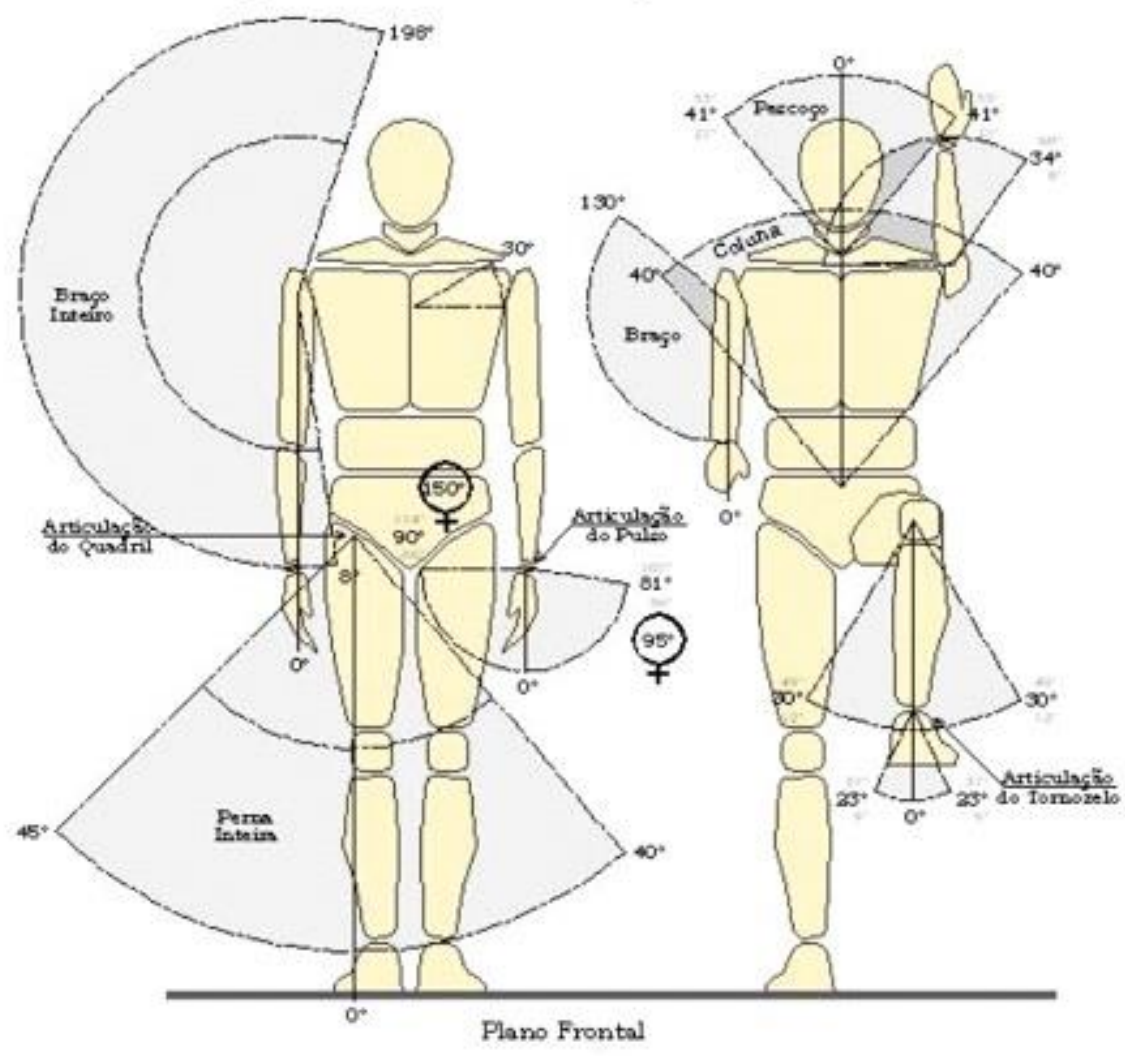

Fonte: Boueri, 2010 , p.64

As Figuras 5, 6, 7 e 8 demonstram o mesmo conceito mas sob a ótica de Iida, sendo que este autor subdivide as medições em: movimentos da coluna vertebral, do ombro, do cotovelo e do quadril e joelhos.

A variável dinâmica do corpo quanto à coluna, destaca-se a mobilidade da cintura com o tronco para as laterais, para frente e para trás, além da possibilidade de rotação do tronco (Figura 5). 
Figura 5: Medida do corpo dinâmica /Coluna Vertebral
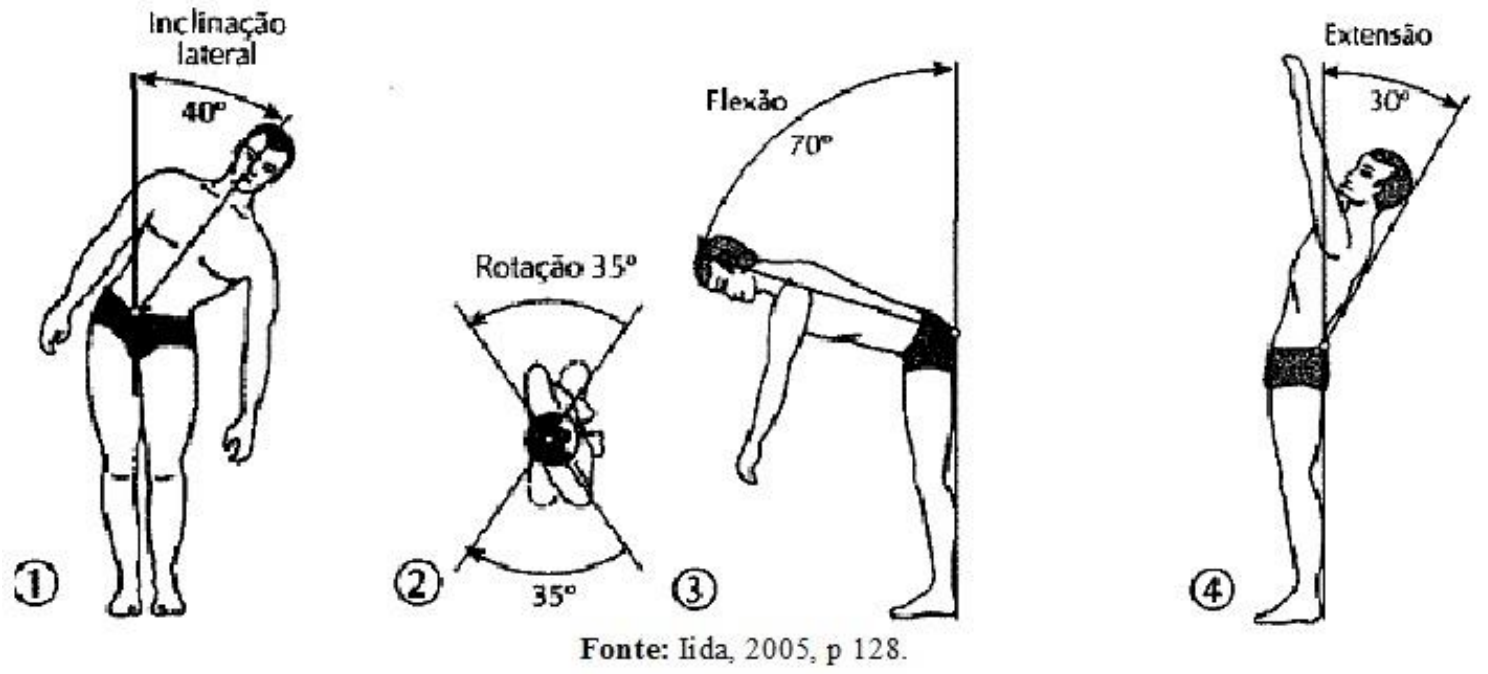

A Figura 6 evidencia a movimentação dos ombros, frontal, lateral e rotacional, sendo que este possibilita uma rotação ampla dos braços.

Figura 6: Medida do corpo dinâmica /Ombro
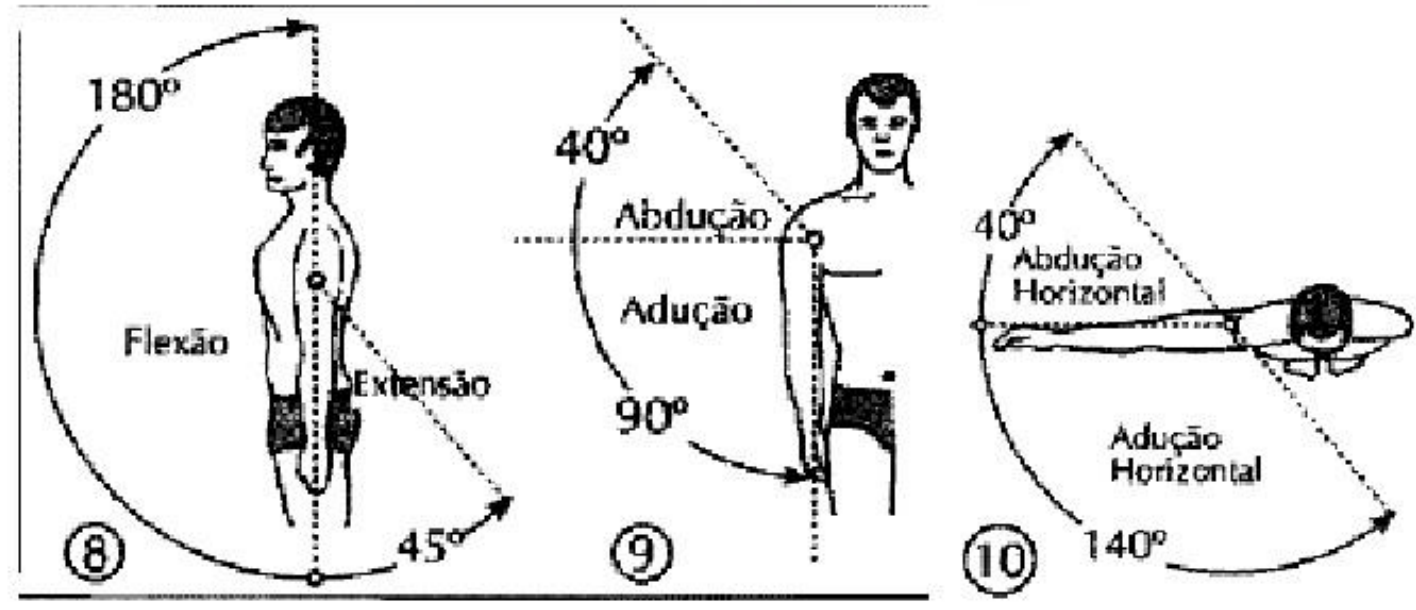

Fonte: Iida, 2005, p. 128 
Figura 7: Medida do Corpo dinâmica /Cotovelo

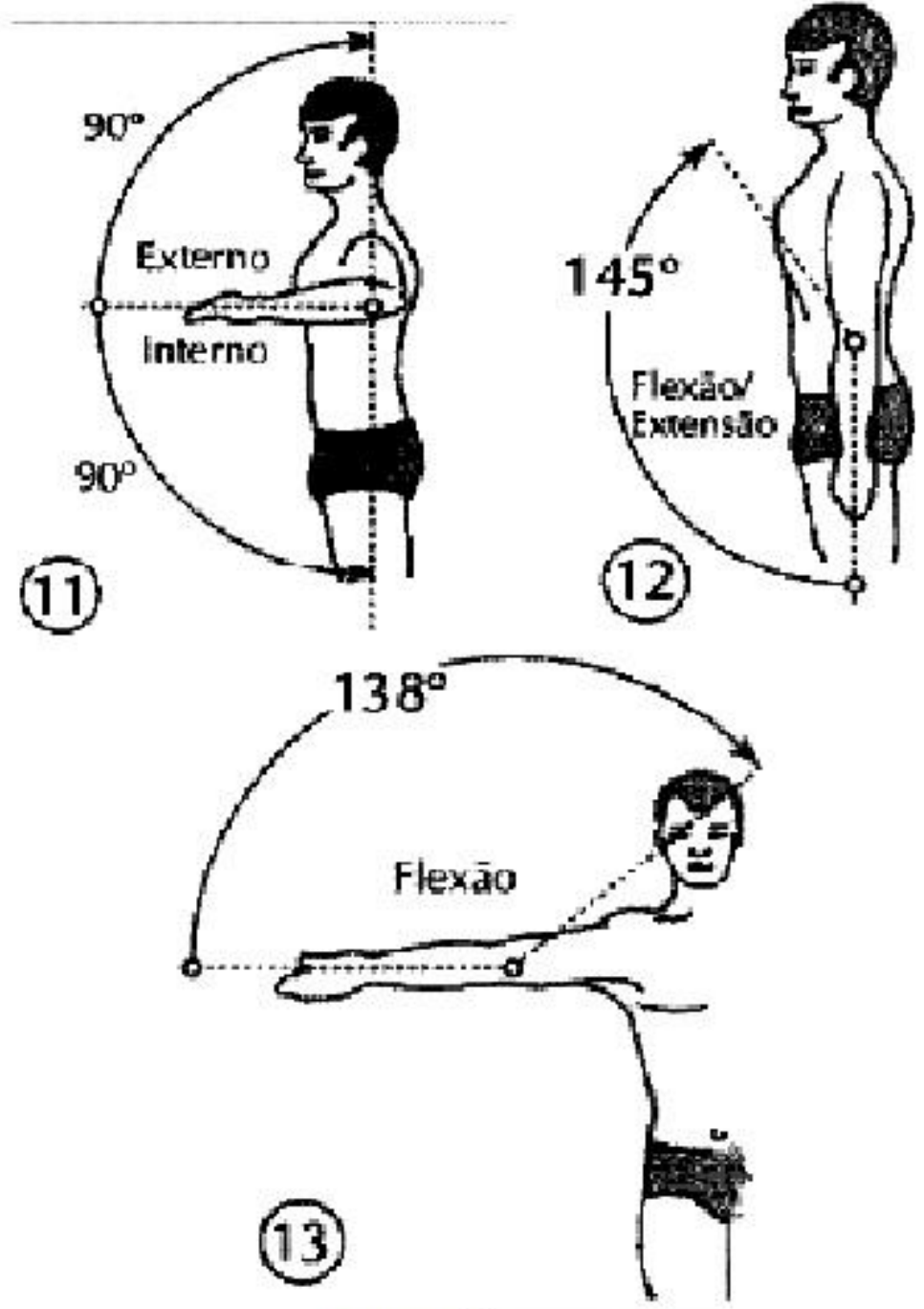

Fonte: Iida, 2005, p.128.

Complementando os movimentos dos braços, visualiza-se a ação da articulação do cotovelo, apresentada na Figura 7, cuja junção também abrange grandes rotações que acrescentam as atividades exercidas pelo braço, carecendo de grande atenção pelos profissionais que criam os produtos do vestuário.

Nas variáveis da antropometria dinâmica apresentada na Figura 8, estão as possibilidades de rotação e ação do quadril e do joelho, sendo a perna outro elemento a ser considerado e observado atentamente pelos profissionais do vestuário a fim de aperfeiçoar seus produtos. 
Figura 8: Medida do corpo dinâmica / Quadril e Joelhos

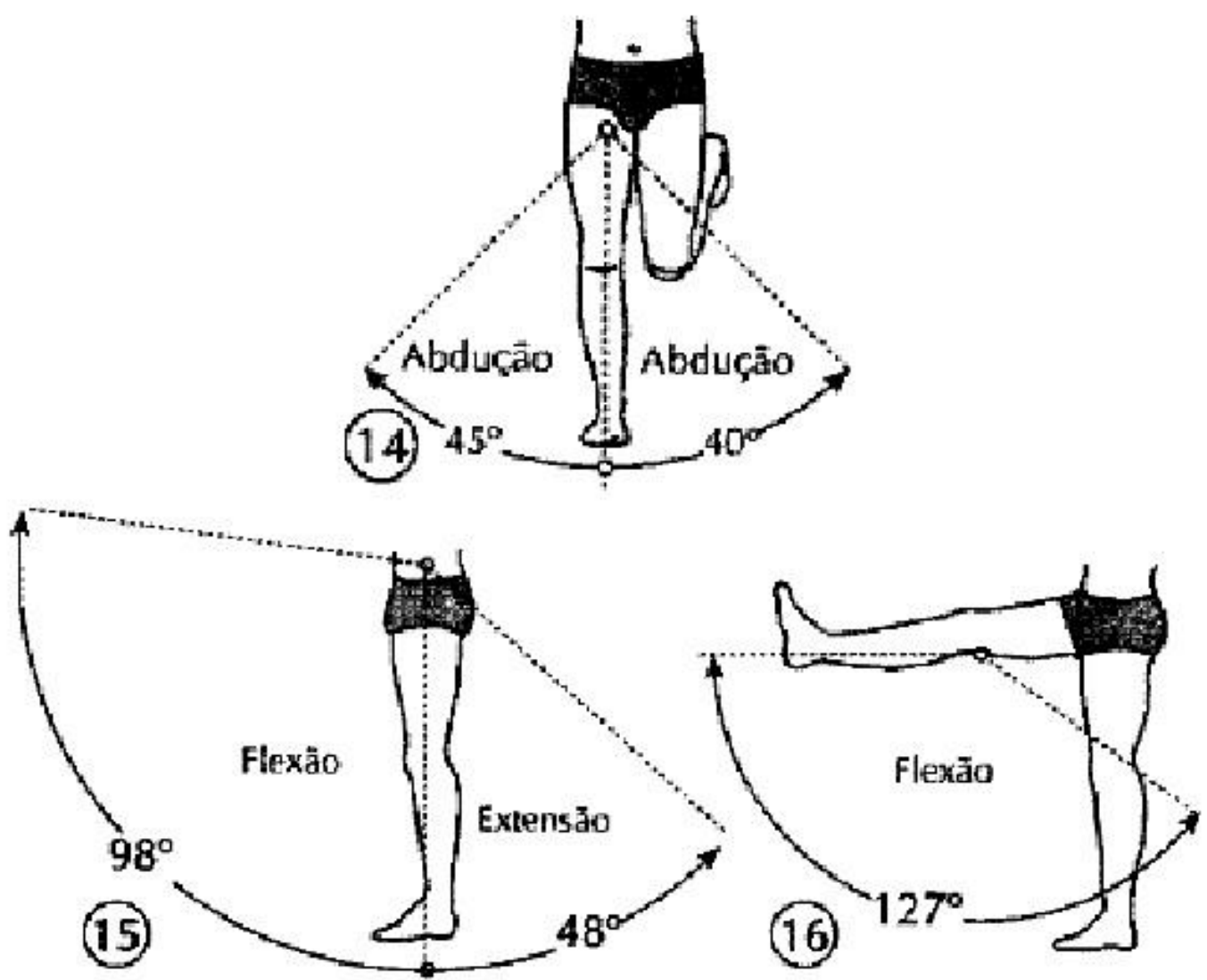

Fonte: Iida, 2005, p.128.

Como já observado, para lida (2005) existem diferenças entre a antropometria Dinâmica e a Funcional. Nas figuras apresentadas, demonstram-se exclusivamente as variáveis de rotações voluntárias do corpo contempladas pela antropometria Dinâmica.

Os dois autores abordam praticamente as mesmas variáveis dinâmicas da antropometria, apesar de Iida apresentá-las detalhadamente, ficando mais simples a sua compreensão.

Destaca-se o conhecimento destas dimensões para auxiliar o designer do produto e o modelista quando forem analisar as tarefas do usuário, unindo mais de uma variável para a projeção do produto.

Para o produto de design de moda, todos os registros retirados a partir das medições antropométricas podem ser relevantes em algum momento do desenvolvimento do produto, podendo ser na etapa da geração de alternativas, nas especificações e detalhamento do produto ou na modelagem. 


\section{Análise de Tarefas}

Baxter (2000), ao examinar a interface homem-produto em detalhe, afirma que esta interface geralmente é complexa e pouco compreendida. Para ele, a análise de atividade observa a relação entre o objeto e o seu usuário, sendo uma fonte de inspiração para o projeto de produto. Os resultados dessas análises podem ser utilizados para inovações nos produtos ou em seus conceitos, aplicando métodos ergonômicos e antropométricos, visando uma melhora da interface homem-produto.

$\mathrm{O}$ autor atenta também para o fato de que é importante observar como as pessoas utilizam os produtos e perguntar como elas os percebem durante o seu uso. Para ele questões que emergem através da análise da ação do usuário devem ser examinadas profundamente, sendo sempre necessário realizar testes naquelas ocasiões em que as pessoas utilizam versões alteradas dos produtos (BAXTER, 2000).

No entanto, considera-se a atividade exercida pelo usuário no momento da utilização da roupa em questão, pois existem peças específicas para cada ocasião, como por exemplo, uma roupa para prática de corrida, o uniforme de trabalho ou mesmo uma peça destinada ao lazer. Com uma proposta bem direcionada e o conhecimento aprofundado do público, o designer dos produtos de moda tem que se atentar aos movimentos exigidos e realizados pelo usuário do objeto, durante o uso da peça do vestuário.

De acordo com Martins (2008), atividades cotidianas como abaixar, levantar, sentar, alcançar, esticar, ou mesmo a alteração do peso corporal correspondem às características ergonômicas de segurança, que possibilita desempenhar com eficiência todo e qualquer movimento da atividade humana. Observa-se que, além destas, existem diversas ações que o ser humano é capaz de realizar e que devem ter suas devidas atenções durante o desenvolvimento do produto, uma vez que a roupa é um item que está em contato direto com a pele e necessita proporcionar a autonomia das ações realizadas pelos usuários.

Segundo Boueri (2008), aquele que projeta o produto, neste caso, o de moda, não é obrigado a ser um especialista em anatomia, mas é necessário que compreenda o básico da estrutura músculo-esquelética e da amplitude de articulação e 
mobilidade do corpo, isto é essencial para uma interpretação exata das dimensões corporais.

A Figura 9 apresenta os elementos da estrutura do corpo humano que o estilista e o modelista devem compreender, considerando as articulações e os movimentos corporais. 
Figura 9: Estrutura do Corpo Humano e Articul ações

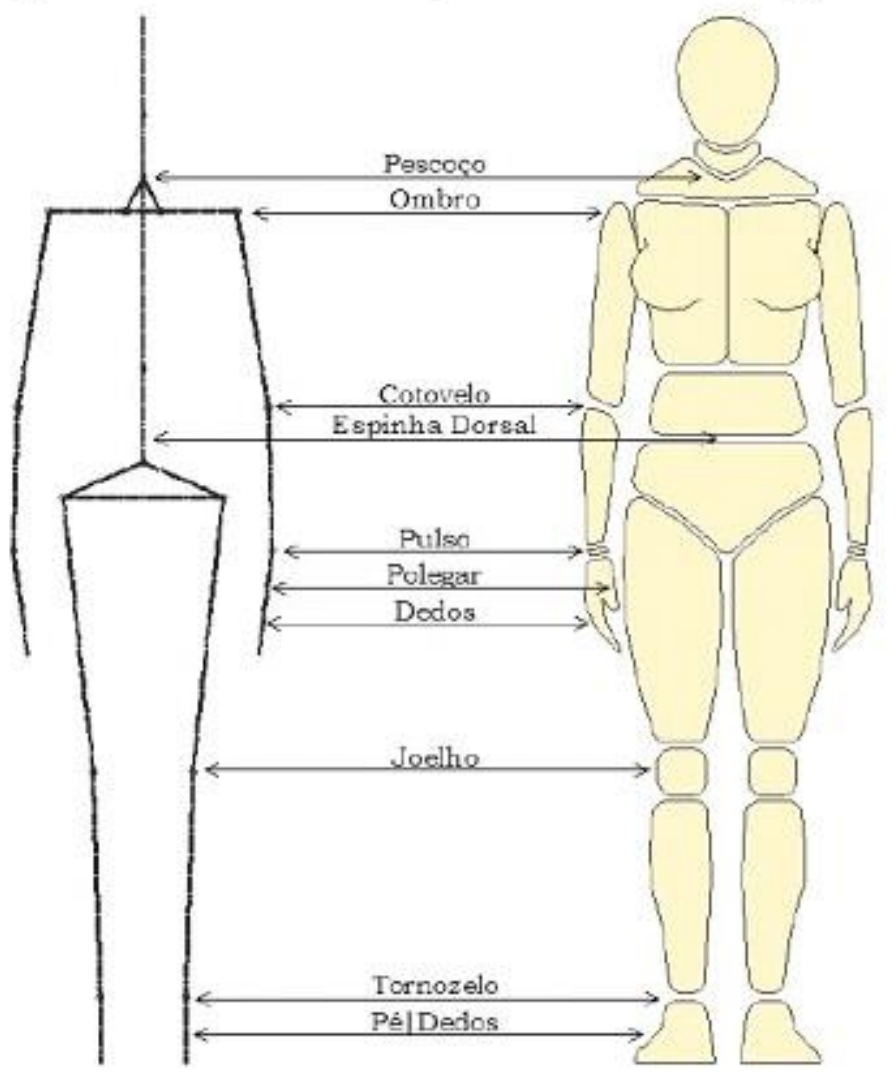

\begin{tabular}{|c|c|c|}
\hline \multicolumn{2}{|c|}{ Articulaçōes } & $\begin{array}{l}\text { Planos de } \\
\text { Liberdade }\end{array}$ \\
\hline \multicolumn{2}{|c|}{ Pescoço } & 3 \\
\hline \multicolumn{2}{|c|}{ Espinha Dorsal } & 3 \\
\hline \multicolumn{2}{|c|}{ Ombro } & 3 \\
\hline \multicolumn{2}{|c|}{ Cotovelo } & 1 \\
\hline \multicolumn{2}{|c|}{ Pulso } & 3 \\
\hline \multirow{5}{*}{ Mào } & \multirow{2}{*}{ Dedos } & 2 \\
\hline & & 1 \\
\hline & \multirow{3}{*}{ Polegar } & 1 \\
\hline & & 1 \\
\hline & & 2 \\
\hline \multicolumn{2}{|c|}{ Quadril } & 3 \\
\hline \multicolumn{2}{|c|}{ Joelho } & 1 \\
\hline \multicolumn{2}{|c|}{ Tornozelo } & 3 \\
\hline \multicolumn{2}{|c|}{ Pé|Dedos } & 2 \\
\hline
\end{tabular}

Fonte: Boueri, 2010, p.65.

Aliando este conhecimento, do corpo e suas articulações, com as medições obtidas através da antropometria, o designer de moda pode alcançar melhores resultados. 


\section{Considerações Finais}

No presente artigo ressalta-se um ponto que poucas vezes é levado em consideração no processo de elaboração e desenvolvimento do produto de moda: a análise das tarefas exercidas pelo usuário no momento do uso da roupa.

Buscou-se aprofundar o conhecimento sobre o desenvolvimento do produto de moda, a sua modelagem, ergonomia e antropometria, as tarefas do usuário a fim de reunir teorias e associá-las ao produto de moda, demonstrando a importância deste tipo de análise para um bom desempenho do produto do vestuário.

No momento do planejamento, devem estar inseridas praticamente todas as informações sobre o público-alvo, tanto a faixa etária, gênero, classe social, como atividades exercidas, gosto, estilo, entre outros, e a partir do conhecimento aprofundado sobre o seu usuário é que o designer será capaz de inovar em seu produto, sendo na sua funcionalidade, no seu estilo, e/ou também na sua configuração/shape.

A funcionalidade do produto é um item muito provável de ser ampliado quando são analisados os movimentos exercidos durante o uso da roupa, pois além de vestir, a roupa pode auxiliar com mais alguma função. Além da possibilidade do designer de moda recriar várias alternativas para o vestuário, nada o impede de inovar apenas no estilo, na modelagem, ou meramente uma alteração de material têxtil.

A ergonomia e antropometria auxiliam desde a concepção da ideia até a conclusão do produto, uma vez que seus princípios devem ser considerados inerentes ao projeto, visando uma modelagem de excelência e uma roupa diferenciada, segura, prática e confortável.

Cabe ressaltar também que ainda são poucos os estudos que relacionam a análise de tarefas do usuário como um fator a ser estudado durante a concepção e projeção do vestuário. Por outro lado, já não se justifica afirmar que não existem referências antropométricas para aplicação em projetos, especialmente no Design de Moda. Por outro lado, inúmeros outros estudos e levantamentos antropométricos deverão ser realizados, visando especificar outras variáveis dimensionais ainda não exploradas, mas igualmente importantes para a usabilidade dos mais diferentes vestuários. 


\section{Artigo recebido em Setembro de 2015. Aprovado em Maio de 2016 \\ DOI:http://dx.doi.org/105965/1982615x10192016179}

\section{Referências}

BAXTER, M. Projeto de produto: guia prático para o design de novos produtos. São Paulo: Editora Blucher, 2000.

BOUERI, J. J. A contribuição da ergonomia na formação do arquiteto: o dimensionamento dos espaços da habitação. 2004. Tese de Livre Docência, FAU/USP, São Paulo.

BOUERI, J. J. Sob medida: antropometria, projeto e modelagem. In: PIRES, D.B. Design de Moda: olhares diversos. Barueri: Editora Estação das Letras e Cores, 2008, p. 347- 370 .

BOUERI, J. J. Antropometria Aplicada ao Projeto e Dimensionamento do Vestuário Brasileiro. 2010. Relatório Científico Final Projeto Fapesp, EACH USP, São Paulo.

GOMES FILHO, J. Design do objeto: bases conceituais. São Paulo: Editora Escrituras, 2006.

IIDA, I. Ergonomia: projeto e produção. São Paulo: Editora Blucher, 2005.

JONES, S. J. Fashion Design: manual do estilista. São Paulo: Editora Cosac Naify, 2005.

MARTINS, S. B. Ergonomia e moda: repensando a segunda pele. In: PIRES, D.B. Design de Moda: olhares diversos. Barueri: Editora Estação das Letras e Cores, 2008, p. 319 - 336.

MENEGUCCI, F.; SANTOS FILHO, A. G. O design do vestuário para proteção: fatores relevantes no projeto. In: MENEZES, M. S.; MOURA, M. Design de Moda: reflexões no caminho da pesquisa. Bauru: Editora Canal 6, 2013, p.131 - 150.

SANCHES, M. C. F. Projetando moda: diretrizes para a concepção de produtos. In: PIRES, D.B. Design de Moda: olhares diversos. Barueri: Editora Estação das Letras e Cores, 2008, p. 289- 302.

SOUZA, P. M.; MENEZES, M. S. A prática construtiva no âmbito do design de moda: uma experiência projetual. In: MENEZES, M. S.; MOURA, M. Design de Moda: reflexões no caminho da pesquisa. Bauru: Editora Canal 6, 2013, p.93 - 112. 
SPAINE, P. A. A.; MENEZES, M. S. Diretrizes metodológicas para o processo de ensino da modelagem plana industrial do vestuário. In: MENEZES, M. S.; MOURA, M. Design de Moda: reflexões no caminho da pesquisa. Bauru: Editora Canal 6, 2013, p. $41-64$. 